\title{
Effects of zooplankton size and concentration and light intensity on the feeding behavior of Atlantic mackerel Scomber scombrus
}

\author{
William K. Macy*, Sandra J. Sutherland, Edward G. Durbin \\ Graduate School of Oceanography, University of Rhode Island, South Ferry Road, Narragansett, Rhode Island 02882, USA
}

\begin{abstract}
Atlantic mackerel Scomber scombrus had low clearance rates when fed older stage copepodites of the copepod Calanus finmarchicus at high concentrations and high clearance rates at low concentrations. These rates were consistent with filter feeding at high concentrations and particulate feeding at low concentrations. Intermediate and small copepods presented together at high concentrations were cleared at lower rates than the large C. finmarchicus, suggesting lower filtration efficiencies. Intermediate and small copepods were presented over a range of light intensities $\left(8.2 \times 10^{-8}\right.$ to $1.6 \times$ $10^{0} \mu \mathrm{E} \mathrm{m}^{-2} \mathrm{~s}^{-1}$ ). Feeding ratt did not change significantly between $1.6 \times 10^{0}$ and $2.0 \times 10^{-6} \mathrm{\mu E} \mathrm{m}^{-2} \mathrm{~s}^{-1}$, but decreased to nearly zero at $8.2 \times 10^{-8} \mu \mathrm{E} \mathrm{m}^{2} \mathrm{~s} ;$, indicating a light intensity threshold for feeding of about $10^{-7} \mu \mathrm{E} \mathrm{m}^{-2} \mathrm{~s}^{-1}$. This threshold enables mackirel to fied throughout the night near the ocean surface. Swimming speed decreased to a lesser degree than feeding rate at the lowest light intensity, indicating that the change in filter-feeding rate is only partially due to the change in speed. The school dispersed in both low and high light levels, but spacing between fish did not appear to be related to feeding rate
\end{abstract}

KEY WORDS: Mackerel Scomber scombrus Calanus finmarchicus Filter feeding Light intensity (irradiance) - Schooling behavior

\section{INTRODUCTION}

Atlantic mackerel Scomber scombrus is a highly migratory species, wintering offshore at mid-depths from Cape Hatteras to Georges Bank, and migrating as far north as the Gulf of St. Lawrence in the summer (Sette 1950). The spring migration starts in April when the fish first reappear off Cape Hatteras. The fish move northward as the season progresses, crossing Georges Bank during May. They usually follow the $7^{\circ} \mathrm{C}$ isotherm during their migration (Sette 1950, Michaels 1991). At present the stock size of mackerel is very high (nearly 3 million $M t$ in 1990; NEFSC 1995), and large schools of migrating fish have been observed on Georges Bank (Michaels 1991).

Mackerel are planktivores, using both filter and particulate modes of feeding (Pepin et al. 1988). Biting, or

-E-mail: wkmacy@gsosun1.gso.uri.edu particulate feeding, involves the predator chasing and consuming large prey individually. When filter feeding, the predator collects food particles passively by straining water through the gill rakers. Filter feeding usually occurs when prey are small or highly concentrated (Gibson \& Ezzi 1985, James \& Findlay 1989). On Georges Bank, mackerel feed primarily on juvenile sand lance (Ammodytes spp., 26\% by volume), shrimp $(16 \%)$, and copepods $(10 \%)$, with euphausiids, amphipods, and other crustaceans also making up a large portion of their diet (Michaels 1991), probably using both modes of feeding Maximum stomach fullness occurs at dawn and dusk, indicating a diel cycle in feeding activity (Vinogradov 1981).

Atlantic mackerel migrating across Georges Bank during spring may have a strong negative impact on the gadid populations of Georges Bank through predation upon late stage larval and early juvenile cod Gadus morhua and haddock Melanogrammus aeglefi- 
nus which are present in the water column at this time of year (Michaels 1991). The potential predation impact upon the young gadids will depend on the feeding mode the mackerel use when preying upon them (Durbin 1979). Particulate feeding depends highly on the visual abilities of the predator. Volumes searched are large and there is likely to be a strong affect of light on their feeding behavior In contrast, when filter feeding the volume searched is small and the fish are less dependent on vision. This feeding mode may thus become important when there is insufficient light for particulate feeding. Filter feeding has been observed at lower light intensities than particulate feeding in some species (Clupea harengus, Batty et al. 1986; Dorosoma petenense, Holanov \& Tash 1978). Other species can apparently feed under moonlight alone (Trachurus symmetricus, Hunter 1968; Alosa pseudoharengus, Janssen 1978). At present it is unknown whether the rate of filter feeding decreases at low light intensities, or whether the fish continue to feed independently of light intensity until they reach a threshold light level. Batty et al. (1986) found that feeding rates of herring in the dark were only about onethird of those in the light, due to decreased swimming speeds. Other factors which may influence filter-feeding rate include prey concentration, prey size, predator mouth size, pore size of the gill rakers, and the amount of time the predator spends filtering (Durbin 1979), as well as position and spacing of fish within a school since these affect the amount of water that is filtered by multiple fish (Gibson \& Ezzi 1985, Krause 1993).

Atlantic mackerel Scomber scombrus appear to have better visual abilities than many other species, as indicated by their low-light-intensity schooling threshold $\left(1.8 \times 10^{-7} \mu \mathrm{E} \mathrm{m} \mathrm{m}^{-2} \mathrm{~s}^{-1}\right.$; Glass et al. 1986). Other marine species have schooling thresholds ranging from $10^{-3}$ to $10^{-8} \mu \mathrm{E} \mathrm{m}^{-2} \mathrm{~s}^{-1}$ (Whitney 1969). Mackerel have 2 visual pigments in their rod cells, with maximal sensitivity to green/blue light (522 and $487 \mathrm{~nm}$; Dartnall \& Lythgoe 1965). Their eyes adapt to darkness at 10 to $10^{-2}$ lux $\left(10^{-2}\right.$ to $\left.10^{-4} \mu \mathrm{E} \mathrm{m}^{-2} \mathrm{~s}^{-1}\right)$ and have an absolute threshold of $10^{-8} \operatorname{lux}\left(10^{-10} \mu \mathrm{E} \mathrm{m} \mathrm{m}^{-2} \mathrm{~s}^{-1}\right)$ (Blaxter 1976). (See McCree [1981] for information on unit conversion.)

In the present study we carried out experiments to determine the effects of light on swimming speeds and feeding rates of Atlantic mackerel when provided with copepods and larval cod as prey.

\section{METHODS}

One year old mackerel were captured with barbless hooks from Narragansett Bay in September and October 1994 during their southward fall migration. The fish were sedated with quinaldine (Lambert 1982) for transport to the laboratory. Once at the laboratory, a school of 30 fish was maintained in a $2.4 \mathrm{~m}$ diameter, $50 \mathrm{~cm}$ deep tank, located in a light-tight room. The tank was painted black on the inside and was fitted with removable white reflective Scotchlite ${ }^{\mathrm{m}}$ panels. The temperature was maintained at $10^{\circ} \mathrm{C}$ and 30 to $32 \%$. The fish were exposed to a $12 \mathrm{~h}$ light $/ 12 \mathrm{~h}$ dark diel cycle. They were fed finely ground squid and fish once a day, at 5 to $10 \%$ body weight. Survival rates were excellent, and the fish grew from about $18 \mathrm{~cm}$ in October 1994 to an average of $26 \mathrm{~cm}$ FL (fork length) and $184 \mathrm{~g}$ by the end of the experiments (June 1995).

Two types of light were used to provide illumination for the fish: the fluorescent lights $(75 \mathrm{~W}, 5200 \mathrm{~K}$. AquaSun model, Ultraviolet Resources International), which provided normal ambient lighting approximating the spectral composition of natural daylight, and 4 panels of green light-emitting diodes (LEDs; peak wavelength $565 \mathrm{~nm}$, LiteOn brand, \#2057 AG), which were used for low intensity illumination. Light intensities were measured with an International Light 1700 radiometer equipped with a SHUD033 detector, a PAR (photosynthetically active radiation) filter (400 to $700 \mathrm{~nm}$ ), and a cosine correction diffuser. The detector was placed underwater at the bottom center of the tank for all measurements. A calibration curve relating light intensity to LED current was then developed and used in the experiments (Sutherland 1996). All light measurements were made with a water depth of $25 \mathrm{~cm}$. The highest test light level $\left(1.6 \mu \mathrm{E} \mathrm{m}^{-2} \mathrm{~s}^{-1}\right)$ was obtained with the fluorescent lights. Regulating current to the LEDs provided the intermediate light levels $\left(2.0 \times 10^{-6}\right.$, $1.6 \times 10^{-5}$, and $2.7 \times 10^{-4} \mu \mathrm{E} \mathrm{m}^{-2} \mathrm{~s}^{-1}$ ). With all lights off, the measured light intensity in the room was $8.2 \times 10^{-8}$ $\mu E \mathrm{~m}^{-2} \mathrm{~s}^{-1}$. Table 1 lists some natural light conditions for comparison.

Two video-cameras were placed above the tank, one viewing the entire tank from directly overhead and the other providing a close-up view of a small portion of

Table 1. Natural equivalents of light intensities in the open ocean. Data are for the water's surface or for clear water. (After Glass et al. 1986)

\begin{tabular}{|cc|}
\hline $\begin{array}{c}\text { Light intensity } \\
\left(\mu \mathrm{E} \mathrm{m} \mathrm{m}^{-2} \mathrm{~s}^{-1}\right)\end{array}$ & Natural equivalent \\
\hline $2 \times 10^{3}$ & Unobscured sun $\left(57^{\circ} \mathrm{N}\right)$ \\
$10^{1}$ & Sunrise/sunset \\
$10^{-3}$ & Full moon \\
$10^{-4}$ & Half moon \\
$10^{-5}$ & Maximum starlight $(0 \mathrm{~m})$ \\
$10^{-6}$ & Bioluminescence \\
$10^{-5}$ & Starlight $(20 \mathrm{~m})$ \\
$10^{-7}$ & Starlight $(40 \mathrm{~m})$ \\
$10^{-8}$ & Starlight $(60 \mathrm{~m})$ \\
\hline
\end{tabular}


the tank. For low light experiments, lamps fitted with near-infrared transmitting filters were used to provide illumination for the cameras. These lights had a minimum transmittance of $780 \mathrm{~nm}$, which was not visible to the fish. For swimming speed determination, the overhead video camera was calibrated by taking video images of a submerged plastic grid of known dimensions placed $12.5 \mathrm{~cm}$ above the bottom of the tank (mid-water depth).

Experimental protocol. At least $12 \mathrm{~h}$ prior to each experiment, the Scotchliterm reflective panels were placed on the bottom of the tank. Water depth was decreased from 50 to $25 \mathrm{~cm}$, over a period of 20 to $30 \mathrm{~min}$, to reduce the quantity of zooplankton necessary to attain the test concentrations. The fish were starved for $24 \mathrm{~h}$ before experiments. The fish were preconditioned to the initial test light intensity for a minimum of $1 \mathrm{~h}$ prior to the onset of experiments. All experiments were run during the day and early evening. At least 20 min were allowed for the fish to acclimate to subsequent new test light intensities, in the manner of Glass et al. (1986). A 5 min video-recording of the routine behavior of the fish was made prior to each experiment.

The video equipment was turned on immediately before prey were added to the tank, and was left on throughout the experiment. Live zooplankton prey were added at 4 locations around the perimeter of the tank. The tank was then mixed thoroughly with 2 clear plastic disk plungers, moved vertically through the water and around the tank. Surprisingly, the fish were not greatly disturbed by the mixing. They normally resumed feeding within 1 min after the mixing was complete. Immediately after mixing, nine 21 water samples were taken by dipping glass jars to the bottom of the tank and then lifting them out full. These 9 samples were taken in a cross pattern within the tank, with 1 sample from the tank's center, and the remainder taken in 4 lines spaced $90^{\circ}$ apart. One sample in each line was taken at mid-radius and the other near the edge of the tank. Mixing and sampling were repeated every $5 \mathrm{~min}$, generally for a minimum of 3 intervals (Table 2). Periods of mixing and sampling were excluded from the elapsed time. The samples were concentrated to volumes of 50 to $100 \mathrm{ml}$ and preserved in $4 \%$ buffered formalin. The copepods in each sample were later identified to species and counted, and the mean concentration of each set of 9 samples determined.

An initial series of experiments (L-Oa through L-Oe) was carried out at high light $\left(1.6 \mu \mathrm{E} \mathrm{m}^{-2} \mathrm{~s}^{-1}\right)$ and at a range of zooplankton concentrations (Table 2). At the end of each experiment, the threshold concentration for the termination of feeding was determined. In this first experimental series, the zooplankton were primarily large, lipid-rich overwintering Calanus finmarchi- cus (see below for more complete description of zooplankton prey and size groupings). Young cod larvae were next offered to the mackerel in several experiments (Table 2). In the first experiment (TF-0a), $3 \mathrm{~d}$ old larvae which still had some yolk (mean length $5.3 \mathrm{~mm}$ ) were offered at a concentration of $4^{-1}$ In a second experiment (TF-0b), 5 d old larvae which had no yolk (mean length $5.1 \mathrm{~mm}$ ) were offered at a concentration of $22 \mathrm{l}^{-1}$. In a third experiment (LSF-0), cod larvae were offered together with large and small copepods. A series of experiments were then carried out to determine the effect of light intensity on the feeding and swimming behavior of mackerel. The zooplankton in these experiments was a mixture of intermediate and small copepods. Finally, experiments were carried out to determine the effect of light level on the threshold concentration of prey for initiation of feeding.

Prey size. Live zooplankton for the experiments were collected on an opportunistic basis on research cruises to the southern Gulf of Maine, and, as a result, sequencing of experiments was dependent on a rather irregular supply of prey. The zooplankton was collected with a $333 \mu \mathrm{m}$ mesh net, which selected only the larger members of the zooplankton. However, during the course of the experiments the available prey field changed considerably, making it difficult replicate oxperiments.

In sample analysis, copepods were identified to species and developmental stage and grouped into 1 of 3 size categories: Large, Intermediate, and Small. The Large size category consisted primarily of stages C4 to C6 overwintering Calanus finmarchicus. Intermediate included actively growing $C$. finmarchicus C4 to C6 and $\mathrm{C} 6$ Centropages typicus, while the Small category consisted of C. finmarchicus C1 to C3, C. typicus C4 to C5, and C4 to C6 Paracalanus sp. and Clausocalanus $\mathrm{sp}$. Although the $C$. finmarchicus in both the Large and Intermediate categories were similar in length and developmental stage, these 2 groups were separated because overwintering $C$. finmarchicus collected during the fall have about twice the carbon content as actively growing and reproducing animals captured during the winter and spring (Tande 1981).

Neither length nor carbon content of the copepods within each size grouping was measured directly in. this study. Approximate mean cephalothorax lengths for taxa within these groupings were calculated from. data presented in Murphy \& Cohen (1978) and are as follows: $2.02 \mathrm{~mm}$ (Large), $1.66 \mathrm{~mm}$ (Intermediate), and $0.81 \mathrm{~mm}$ (Small). Dry weights from Comita et al. (1966), Tande (1981), Davis (1992), and our own unpublished data were estimated to be: $300 \mu g$ (Large), $150 \mu \mathrm{g}$ (Intermediate), and $30 \mu \mathrm{g}$ (Small)

Swimming speed and schooling behavior. To identify possible factors affecting the volume swept clear 
Table 2. Initial conditions for each experiment. Experiment names indicate: first, the prey type(s) avallable (Large, Intermediate or Small copepods, or Fish larvae); second, the exponent of the light intensity; and last, lower-case letters indicate replicates where appropriate. In some cases, the letter ' $T$ ' is used to indicate experiments used to determine thresholds for initiation of feeding. Mean prey concentrations and $95 \%$ confidence limits are listed

\begin{tabular}{|c|c|c|c|c|c|c|c|c|}
\hline \multirow[t]{2}{*}{ Expt } & \multirow[t]{2}{*}{ Date } & \multirow{2}{*}{$\begin{array}{c}\text { Elapsed } \\
\text { time } \\
\text { (min) }\end{array}$} & \multirow{2}{*}{$\begin{array}{c}\text { Number } \\
\text { of } \\
\text { fish }\end{array}$} & \multirow{2}{*}{$\begin{array}{c}\text { Light } \\
\text { intensity } \\
\left(\mu \mathrm{E} \mathrm{m}^{-2} \mathrm{~s}^{-1}\right)\end{array}$} & \multicolumn{4}{|c|}{ Initial prey concentration (no. $1^{-1}$ ) } \\
\hline & & & & & Large & Intermediate & Small & Fish larvae \\
\hline \multicolumn{9}{|c|}{ Prey concentration experiments } \\
\hline L-Oa & 18 Nov 1994 & 24 & 30 & $1.6 \times 10^{0}$ & $63.6 \pm 13.4$ & & & \\
\hline $\mathrm{L}-\mathrm{Ob}$ & 20 Nov 1994 & 10 & 30 & $1.6 \times 10^{0}$ & $23.9 \pm 3.6$ & & & \\
\hline $\mathrm{L}-\mathrm{OC}$ & 19 Nov 1994 & 6 & 30 & $1.6 \times 10^{0}$ & $4.8 \pm 1.4$ & & & \\
\hline$L-O d$ & 19 Nov 1994 & 5 & 30 & $1.6 \times 10^{0}$ & $4.2 \pm 1.3$ & & & \\
\hline $\mathrm{L}-\mathrm{Oe}$ & 19 Nov 1994 & 3 & 30 & $1.6 \times 10^{0}$ & $1.8 \pm 1.0$ & & & \\
\hline LSF-0 & $4 \mathrm{Dec} 1994$ & 21 & 30 & $1.6 \times 10^{0}$ & $89.5 \pm 12.9$ & & $57.5 \pm 7.1$ & $7.8 \pm 1.4$ \\
\hline \multicolumn{9}{|c|}{ Feeding threshold experiments } \\
\hline TF-0a & 30 Nov 1994 & & 30 & $1.6 \times 10^{0}$ & & & & $3.9 \pm 1.1$ \\
\hline TF-Ob & 30 Nov 1994 & & 30 & $1.6 \times 1.0^{0}$ & & & & $21.5 \pm 3.7$ \\
\hline TL-0 & 4 Jun 1995 & & 27 & $1.6 \times 10^{0}$ & $4.4 \pm 1.7$ & & & \\
\hline TL-5 & 4 Jun 1995 & & 27 & $2.4 \times 10^{-5}$ & $9.6 \pm 2.3$ & & & \\
\hline TL-6 & 4. Jun 1995 & & 27 & $4.2 \times 10^{-6}$ & $10.0 \pm 2.3$ & & & \\
\hline TL-7 & 4 Jun 1995 & & 28 & $1.2 \times 10^{-7}$ & $12.7 \pm 3.7$ & & & \\
\hline TL-8 & 4 Jun 1995 & & 27 & $8.2 \times 10^{-8}$ & $14.7 \pm 3.3$ & & & \\
\hline \multicolumn{9}{|c|}{ Light intensity experiments } \\
\hline IS-Oa & 24 Mar 1995 & 16 & 27 & $1.6 \times 10^{0}$ & & $49.2 \pm 14.0$ & $72.9 \pm 18.9$ & \\
\hline IS-Ob & 10 Mar 1995 & 10 & 27 & $1.6 \times 10^{0}$ & & $41.2 \pm 13.1$ & $43.6 \pm 12.0$ & \\
\hline IS-4 & 10 Mar 1995 & 21 & 27 & $2.7 \times 10^{-4}$ & & $55.9 \pm 12.3$ & $65.6 \pm 13.7$ & \\
\hline IS-5 & 10 Mar 1995 & 19 & 27 & $1.6 \times 10^{-5}$ & & $30.9 \pm 5.5$ & $38.3 \pm 6.7$ & \\
\hline $1 S-6 a$ & 20 Feb 1995 & 16 & 28 & $2.0 \times 10^{-6}$ & & $70.6 \pm 11.3$ & $69.2 \pm 10.0$ & \\
\hline IS $-6 b$ & 24. Mar 1995 & 15 & 27 & $2.0 \times 10^{-6}$ & & $53.2 \pm 10.4$ & $72.5 \pm 8.0$ & \\
\hline IS $-8 \mathrm{a}$ & 20 Feb 1995 & 22 & 28 & $8.2 \times 10^{-8}$ & & $52.3 \pm 20.7$ & $54.9 \pm 15.8$ & \\
\hline IS $-8 b$ & $24 \operatorname{Mar} 1995$ & 16 & 27 & $8.2 \times 10^{-8}$ & & $37.5 \pm 9.5$ & $52.1 \pm 12.3$ & \\
\hline
\end{tabular}

(VSC), both the swimming speed and the spacing of fish in the school were measured from the videotapes of the experiments using an image-analysis program (OPTIMAS ${ }^{\mathrm{m}}$; BioScan 1992), Both routine (prior to feeding) and feeding activity were examined. All measurements were taken in the first 5 min interval of each feeding experiment, except in Expt IS-8a. In this case, initiation of feeding appeared to be delayed, so measurements were taken in the second interval. Samples were taken in the middle of the interval to reduce the effects of mixing and sampling on fish behavior.

Swimming speed was determined by measuring successive $x-y$ coordinates of a single fish at $0.5 \mathrm{~s}$ intervals for a duration of $3 \mathrm{~s}$ (= 1.5 video frames) and then calculating the mean speed over this period. A total of 10 fish were measured in this way, yielding 10 measurements of swimming speed for each test interval. Coefficients of variation and standard deviations remained the same for sample sizes from 10 to 25 fish, indicating that the low sample size used was sufficient for accurate swimming-speed measurements.

Spacing of fish within the school could not be measured by nearest-neighbor distances, due to vertical overlap of fish. Instead, the subtended angle of the school was measured in all the light-intensity experi- ments. This angle was the angle from the front fish in the school, to the center of the tank, to the rear-most fish, and can be considered a measure of school length. Measurements were made 6 times in each experiment, at intervals of $15 \mathrm{~s}$. Again, larger sample sizes failed to reduce variability, and thus were not used.

Feeding initiation and termination thresholds. To determine threshold prey concentration levels for initiation of feeding as a function of light level, the fish were acclimated for at least 20 min to the test light level. Large copepods were then addect to yield tank concentrations of about 5 copepods $\mathrm{l}^{-1}$, and the tank was mixed. An initial set of nine 21 water samples was taken, and the fish were then observed. If at least $50 \%$ of the fish began to feed within $2 \mathrm{~min}$, as evidenced by their flared gill opercula and open mouths, it was decided that the concentration was at the threshold level, and the experiment was ended. Otherwise, additional prey were added in $51^{-1}$ increments, and samples were taken after each addition until the fish began feeding. The final sample, taken when $50 \%$ or more of the fish were feeding, was preserved in $4 \%$ buffered formalin and counted. Threshold feeding termination prey concentrations were determined by observing the fish until at least $50 \%$ had ceased to feed and then taking nine 2 I 
water samples to establish the prey concentration. The copepods in each sample were then preserved and counted, as above. Feeding termination thresholds were only measured at the highest light level.

Determination of feeding rates. The volume swept clear (VSC), a measure of the feeding rate (Durbin \& Durbin 1975, James \& Findlay 1989), was calculated as follows:

$$
\mathrm{VSC}=V \mathrm{~g} / \mathrm{N}\left(1 \mathrm{fish}^{-1} \mathrm{~min}^{-1}\right)
$$

where $V=$ volume of the tank in liters (as calculated from tank depth) and $N=$ number of fish in the school. In each experiment prey concentrations decreased exponentially and linear regressions were fitted to the natural $\log$ of the concentration versus the elapsed time. The slope of these regressions yielded the instantaneous feeding rate, $g$. In experiments where different size classes of copepods were present together, instantaneous feeding rates were calculated for each size class. Linear regressions and tests of heterogeneity of slopes were run using the Statistical Analysis System (SAS) program (Littell et al. 1991)

Clearance efficiency, $E$, was obtained by comparing the VSC with the total volume of water passing through the gill rakers per minute:

$$
E=1667 \mathrm{VSC} /(\mathrm{SA})(\%)
$$

where $S=$ swimming speed $\left(\mathrm{cm} \mathrm{s}^{-1}\right)$. A constant of 1667 was needed to convert units. Mouth area $(A)$, estimated with MacKay's (1979) regression based on fork length $\left(A=0.0132 \mathrm{FL}^{1.895}\right)$, was calculated to be $5.02 \mathrm{~cm}^{2}$ for a $23 \mathrm{~cm}, 152 \mathrm{~g}$ wet $\mathrm{wt}$ fish (the midpoint of fish size in these experiments).

Ingestion rates were calculated in terms of $\mathrm{g}$ dry weight of prey eaten per $\mathrm{kg}$ fish for the initial $5 \mathrm{~min}$ period using the instantaneous feeding rate, $g$ (Eq. 1). From the linear regressions relating prey concentration to elapsed time, we determined the number of copepods per liter at time $t_{0}\left(\mathrm{C}_{t_{0}}\right)$, the number remaining after the initial $5 \mathrm{~min}\left(\mathrm{C}_{t}\right)$, and then calculated the number eaten per 5 min feeding period. The ingestion rates were then fitted to an Ivlev curve where the ingestion rate, $\mathrm{I}$, is given by:

$$
I=\mathrm{B}_{0}\left\{1-\mathrm{e}^{\left[-\mathrm{B}_{1}\left(\mathrm{C}_{1}-\mathrm{C}_{0}\right)\right\}}\right\} \text { (copepods fish }{ }^{-1} 5 \mathrm{~min}^{-1} \text { ) }
$$

where $B_{0}$ and $B_{1}$ were estimated using non-linear regression (Littell et al. 1991), $C_{1}$ is the copepod concentration (no. $\mathrm{l}^{-1}$ ), and $\mathrm{C}_{0}$ is the threshold concentration for the initiation of feeding.

\section{RESULTS}

In all experiments, the mackerel responded to the addition of prey within a few minutes, by opening their mouths wide and flaring the gill opercula. Each feeding bout appeared to last for a few seconds, although we do not have quantitative data on this matter

\section{Swimming speeds and schooling behavior}

The mean routine swimming speed of the mackerel for all experiments was $28.7 \mathrm{~cm} \mathrm{~s}^{-1}\left(1.25 \mathrm{BL} \mathrm{s}^{-1}\right.$; Table 3 ). The mean routine swimming speeds differed significantly $(\mathrm{p}<0.05$, Tukey $\mathrm{HSD})$ between several experiments. However, there was no relationship between these routine swimming speeds and either light level or sequence in which the experiments were carried out. In all experiments, the fish increased their swimming speed significantly when food was added to the tank ( $p<0.05$, 1 -tailed $t$-test; Table 3, Fig. 1), with an overall mean swimming speed while feeding of $41.5 \mathrm{~cm} \mathrm{~s}^{-1}\left(1.80 \mathrm{BL} \mathrm{s}^{-1}\right)$. Swimming speeds while feeding were significantly lower at the lowest light level compared with almost all the higher-light-level experiments ( $p<0.05$, Tukey HSD; Table 4A, Fig. 1), with a mean of only $32.2 \mathrm{~cm} \mathrm{~s}^{-1}\left(1.40 \mathrm{BL} \mathrm{s}^{-1}\right)$ between these 2 experiments. At higher light levels the mean feeding swimming speed was $44.7 \mathrm{~cm} \mathrm{~s}^{-1}\left(1.94 \mathrm{BL} \mathrm{s}^{-1}\right)$. There was no significant change in feeding swimming speed among the experiments at light levels of $10^{-6} \mu \mathrm{E} \mathrm{m}^{-2} \mathrm{~s}^{-1}$ and higher.

There was an effect of food concentration upon swimming speed in the experiments with large copepods.

Table 3. Scomber scombrus. Routine and feeding swimming speeds of mackerel in each experiment. Mean swimming speeds for the school are given with $95 \%$ confidence limits

\begin{tabular}{|c|c|c|c|}
\hline \multirow[t]{2}{*}{ Expt } & \multicolumn{2}{|c|}{ Swimming speed $\left(\mathrm{cm} \mathrm{s}^{-1}\right)$} & \multirow[t]{2}{*}{$p$-value } \\
\hline & Routine & Feeding & \\
\hline \multicolumn{4}{|c|}{ Prey concentration experiments } \\
\hline $\mathrm{L}-0 \mathrm{a}$ & $39.8 \pm 1.3$ & $54.9 \pm 2.4$ & $<0.001$ \\
\hline$L-0 b$ & $24.7 \pm 1.2$ & $39.1 \pm 2.0$ & $<0.001$ \\
\hline $\mathrm{L}-0 \mathrm{c}$ & $25.2+3.0$ & $32.3 \pm 1.4$ & $<0.001$ \\
\hline L-Od & & $35.8 \pm 2.4$ & \\
\hline $\mathrm{L}-0 \mathrm{e}$ & $25.1 \pm 1.4$ & $29.3 \pm 1.7$ & $<0.001$ \\
\hline $\mathrm{LSF}-0$ & & $57.4 \pm 3.3$ & \\
\hline \multicolumn{4}{|c|}{ Light intensity experiments } \\
\hline IS- $0 \mathrm{a}$ & $22.0 \pm 2.1$ & $45.0 \pm 4.1$ & $<0.001$ \\
\hline IS $-0 b$ & $23.8 \pm 0.8$ & $40.6 \pm 2.9$ & $<0.001$ \\
\hline IS-4 & $28.1 \pm 0.9$ & $46.6 \pm 2.8$ & $<0.001$ \\
\hline IS -5 & $34.7 \pm 3.7$ & $44.7 \pm 3.5$ & $<0.001$ \\
\hline IS-6a & $40.9 \pm 2.0$ & $47.2 \pm 3.1$ & $<0.001$ \\
\hline IS-6b & $28.8 \pm 2.5$ & $44.2 \pm 3.3$ & $<0.001$ \\
\hline IS-8a & $24.8 \pm 1.6$ & $35.5 \pm 1.6$ & $<0.001$ \\
\hline IS-8b & $26.0 \pm 3.0$ & $28.9 \pm 2.7$ & $<0.05$ \\
\hline Overall mean & 28.7 & 41.5 & \\
\hline
\end{tabular}
$\{\alpha=0.05)$. Routine swimming speeds were all significantly lower than feeding speeds $(\mathrm{p}<0.05,1$-tailed Student's $t$-test $)$ 


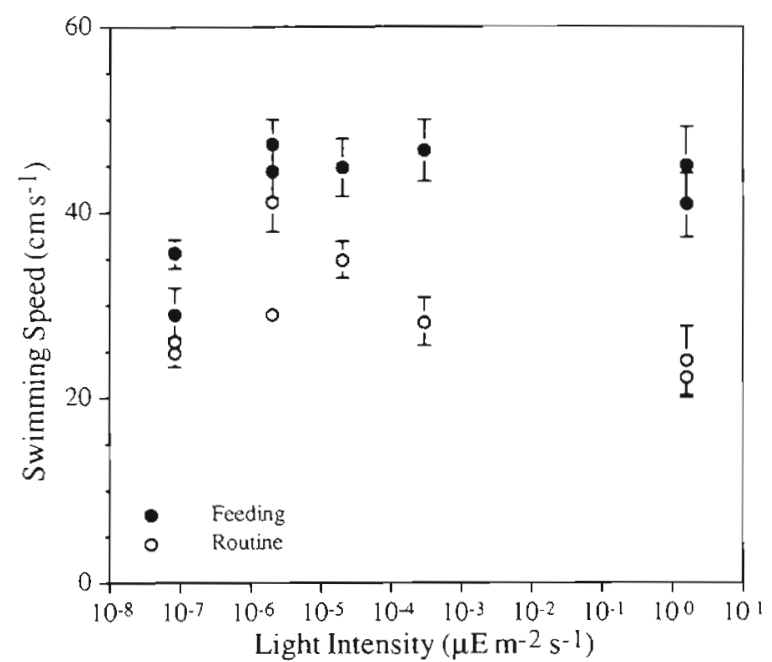

Fig. 1. Scomber scombrus. Routine and feeding swimming speeds of Atlantic mackerel versus light intensity in the lightlevel experiments. Error bars denote $95 \%$ confidence inter. vals for each trial

Swimming speeds were significantly lower at the lowest food concentrations than at the higher food concentrations (Table 4B, Fig. 2). Light was not a factor in these experiments since they were all carried out at high light. When both intermediate and small size classes of copepods were offered together, there was no observed effect of food concentration on swimming speed over the concentration ranges at which they were offered (Fig. 2).

Table 4 . Significance $(\cdot p<0.05)$ of differences in swimming speeds of mackerel while feeding on (A) small and intermediate and (B) large copepod prey (Tukey's Studentized range test). (A) is sorted by decreasing light intensity and (B) by the geometric mean of the prey concentration

(A) Small and intermediate copepod prey IS- $0 a$ IS- $0 b$ IS- 4 IS-5 IS- $6 a$ IS-6b IS-8a IS-8b

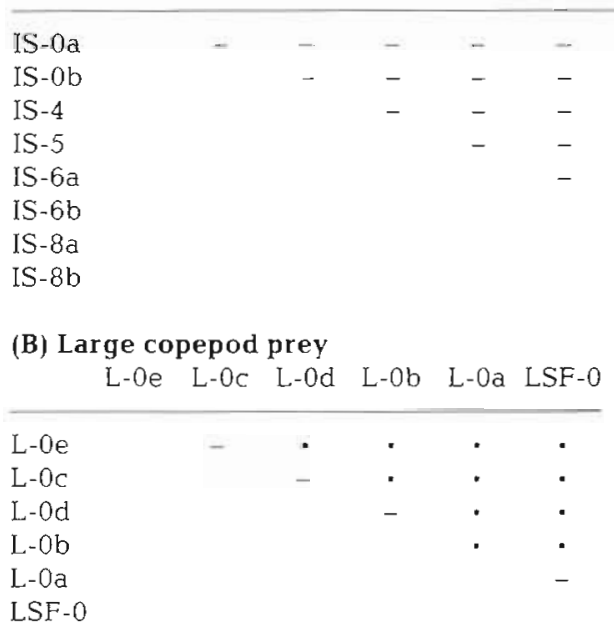

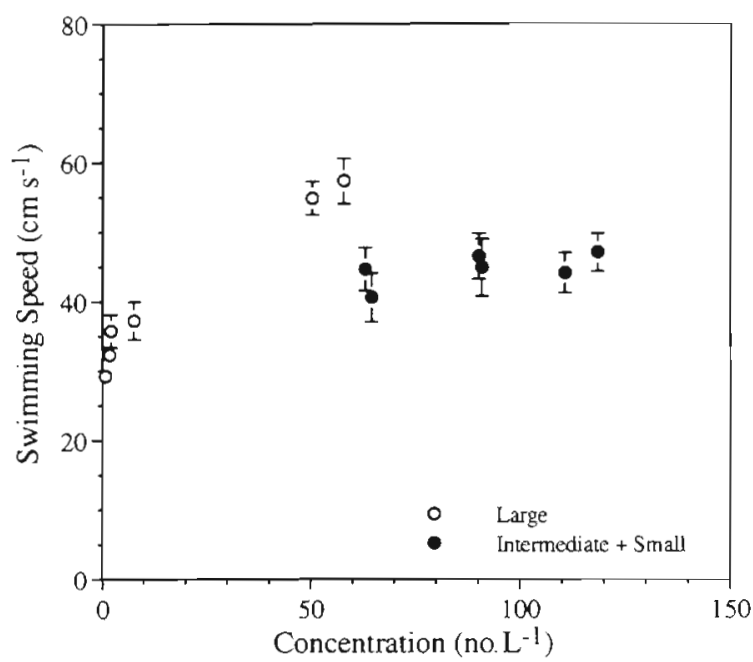

Fig. 2. Scomber scombrus. Swimming speed of Atlantic mackerel as a function of the geometric mean of the prey concentration. Error bars indicate $95 \%$ confidence intervals for each trial. The 2 experiments at the lowest light level are not included here

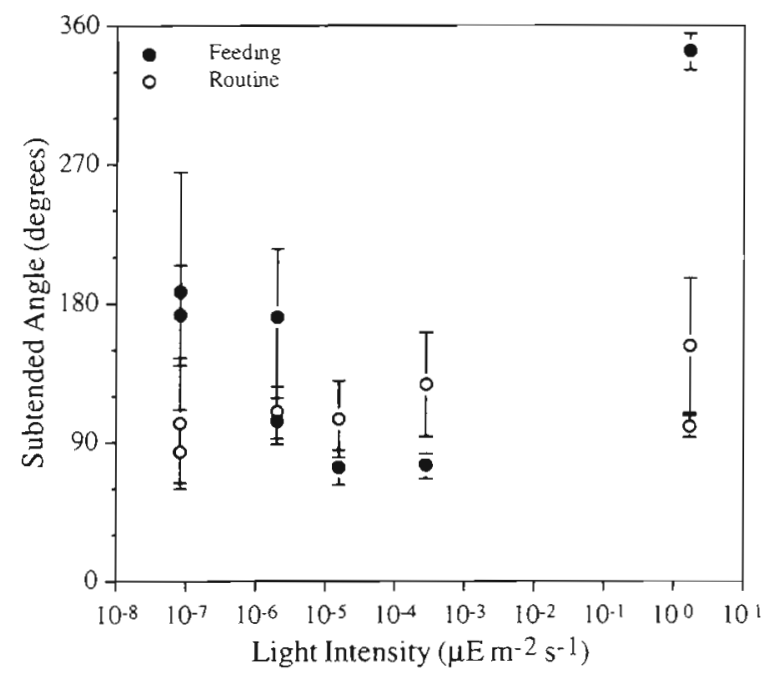

Fig. 3. Scomber scombrus. Subtended angle of the mackerel school during routine activity and during feeding versus light intensity in the light-level experiments. Error bars denote $95 \%$ confidence intervals

When the school was not feeding, the school was dispersed over about a $110^{\circ}$ arc (Fig. 3). This angle did not change over the range of light intensities. However, during feeding, the angle changed significantly. In full light (Expt IS-0a), the school expanded to nearly the full circumference of the tank $\left(342^{\circ}\right)$, a significantly larger angle than at all other light levels $(\mathrm{p}<0.001$, 1 -tailed $t$-test; Table 5). Expt IS-0b was excluded from this analysis because the fish changed behavior during the measurement period, expanding from about $80^{\circ}$ to $335^{\circ}$. At intermediate light levels $\left(10^{-5}\right.$ and $10^{-4} \mu \mathrm{E} \mathrm{m}^{-2}$ 


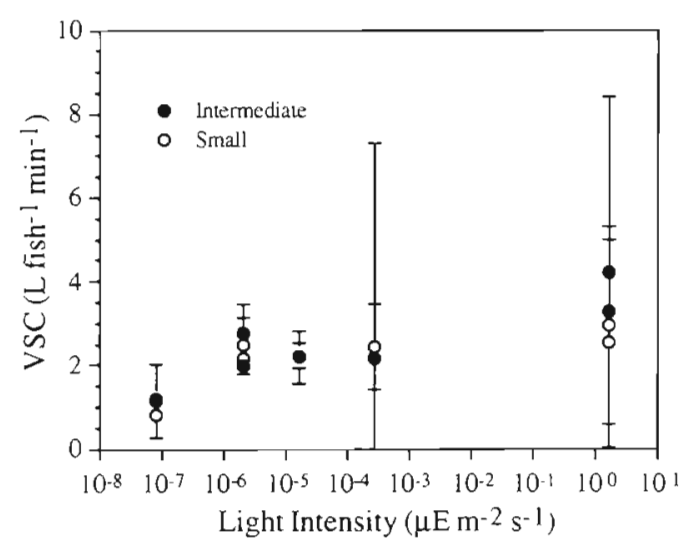

Fig. 4. Scomber scombrus. Effect of light intensity on clearance rate (VSC) of Atlantic mackerel while feeding on intermediate and small copepods. Error bars indicate $95 \%$ confidence intervals

Table 5. Significance of differences in subtended angles while feeding in the light-intensity experiments (2-tailed Student's $t$-test). Experiments are sorted by decreasing light intensity. Levels of significance are: ${ }^{*} 0.01 \leq p<0.05, \cdots 0.001 \leq p<0.01$, $\cdots p<0.001$

\begin{tabular}{|c|c|c|c|c|c|c|c|}
\hline & IS $-0 \mathrm{a}$ & IS -4 & IS-5 & IS-6a & IS-6b & IS-8a & IS-8b \\
\hline IS-0a & & $\cdots$ & $\ldots$ & $\cdots$ & $\cdots$ & $\cdots$ & . \\
\hline IS - 4 & & & - & .. & $\because$ & $\cdots$ & - \\
\hline IS-5 & & & & .. & ". & $\cdots$ & - \\
\hline IS-6a & & & & & • & - & - \\
\hline IS $-6 \mathbf{b}$ & & & & & & $\cdot$ & - \\
\hline IS-8a & & & & & & & - \\
\hline IS $-8 b$ & & & & & & & \\
\hline
\end{tabular}

$\mathrm{s}^{-1}$ ), the subtended angle of the school was consistently $70^{\circ}$. The school dispersed again at the 2 lowest light levels $\left(160^{\circ}, \mathrm{p}<0.05\right)$. Changes in school dispersal were not correlated with changes in feeding rates.

\section{Feeding thresholds}

The mackerel initiated feeding between 4.4 and 14.7 copepods $\mathrm{l}^{-1}$ (Table 6). Initiation thresholds tended to increase with decreasing light level. The mean concentration at which the mackerel terminated feeding was 0.4 copepods $\mathrm{l}^{-1}$ at the highest light level, an order of magnitude lower than the concentration at which they initiated feeding at this same light level (Table 6).

\section{Effects of light upon feeding}

In the light-level experiments, intermediate and small copepods were offered in a relatively narrow range of concentrations at a wide range of light intensities (Table 2). Within each size class, feeding rates at the lowest light intensity $\left(8.2 \times 10^{-8} \mu \mathrm{E} \mathrm{m}^{-2} \mathrm{~s}^{-1}\right)$ were significantly lower than at the higher light levels $(\mathrm{p}<0.05$, heterogeneity of slopes; Table 7. Fig. 4). In one of the highest-light-level experiments (IS-Ob), feeding rate on the intermediate size class of copepods was significantly higher than at all other light levels $(p<0.05$; Table $7 \mathrm{~A})$. In this same experiment, feeding rate on the smaller size

Table 6. Concentrations of large copepods at which feeding was initiated and terminated. For each experiment, the mean of replicate samples taken at the termination of the trial is listed with $95 \%$ confidence limits $(\alpha=0.05)$

\begin{tabular}{|c|c|c|}
\hline Expt & $\begin{array}{l}\text { Light intensity } \\
\left(\mu \mathrm{E} \mathrm{m}^{-2} \mathrm{~s}^{-1}\right)\end{array}$ & $\begin{array}{c}\text { Concentration } \\
\pm 95 \% \mathrm{Cl} \\
\left(\text { no. } l^{-1}\right)\end{array}$ \\
\hline \multicolumn{3}{|c|}{ Feeding initiation } \\
\hline TL-0 & $1.6 \times 10^{0}$ & $4.4 \pm 1.7$ \\
\hline TL-5 & $2.4 \times 10^{-5}$ & $9.6 \pm 2.3$ \\
\hline TL- 6 & $4.2 \times 10^{-6}$ & $10.0 \pm 2.3$ \\
\hline TL-7 & $1.2 \times 10^{-7}$ & $12.7 \pm 3.7$ \\
\hline TL-8 & $8.2 \times 10^{-8}$ & $14.7 \pm 3.3$ \\
\hline \multicolumn{3}{|c|}{ Feeding termination } \\
\hline L-Oa & $1.6 \times 10^{0}$ & $0.5 \pm 0.4$ \\
\hline L-Ob & $1.6 \times 10^{0}$ & $0.1 \pm 0.3$ \\
\hline L-OC & $1.6 \times 10^{0}$ & $0.2 \pm 0.2$ \\
\hline L-Od & $1.6 \times 10^{0}$ & $0.8 \pm 0.6$ \\
\hline $\mathrm{L}-\mathrm{Oe}$ & $1.6 \times 10^{0}$ & $0.4 \pm 0.3$ \\
\hline
\end{tabular}

Table 7. Significance of differences between slopes of the regression equations describing decrease of food with time, for each pair of light-intensity experiments (heterogeneity of slopes). (A) Intermediate and (B) small copepod prey. Experiments are sorted by decreasing light intensity. Levels of significance are: $\cdot 0.01 \leq p<0.05, " \cdot p<0.01$

IS $-0 a$ IS- $0 \mathrm{~b}$ IS-4 IS-5 IS $-6 a$ IS- $6 \mathrm{~b}$ IS $-8 \mathrm{a}$ IS $-8 \mathrm{~b}$

\begin{tabular}{|c|c|c|c|c|c|c|c|}
\hline \multicolumn{8}{|c|}{ (A) Intermediate copepod prey } \\
\hline IS-0a & - & - & - & - & - & $\cdots$ & • \\
\hline IS-0b & & . & . & .. & .. & . & .. \\
\hline IS-4 & & & - & - & - & .. & - \\
\hline IS-5 & & & & $\cdot$ & - & .. & $\cdot$ \\
\hline IS-6a & & & & & $\cdots$ & -. & - \\
\hline IS-6b & & & & & & $\cdot$ & - \\
\hline IS-8a & & & & & & & - \\
\hline IS $-8 \mathrm{~b}$ & & & & & & & \\
\hline \multicolumn{8}{|c|}{ (B) Small copepod prey } \\
\hline IS-0a & - & - & - & - & - & - & . \\
\hline IS-Ob & & - & . & - & . & . & . \\
\hline IS-4 & & & - & - & - & - & .. \\
\hline IS-5 & & & & $\cdot$ & - & $\cdot$ & .. \\
\hline IS-6a & & & & & $\cdot$ & $\cdots$ & . \\
\hline IS-6b & & & & & & - & . \\
\hline IS-8a & & & & & & & - \\
\hline IS-8b & & & & & & & \\
\hline
\end{tabular}


Table 8. Scomber scombrus. Clearance rate (VSC), ingestion rate, and clearance efficiency relative to the geometric mean of the prey concentration for the first $5 \mathrm{~min}$ feeding period of each experiment. Data are sorted by increasing concentration within each prey type

\begin{tabular}{|c|c|c|c|c|c|c|c|}
\hline Expt & $\begin{array}{l}\text { Light intensity } \\
\left(\mu \mathrm{E} \mathrm{m}^{-2} \mathrm{~s}^{-1}\right)\end{array}$ & \multicolumn{2}{|c|}{ Mean concentration } & $\begin{array}{l}\text { VSC } \pm 95 \% \mathrm{CI} \\
\left(\mathrm{l} \mathrm{fish}^{-1} \mathrm{~min}^{-1}\right)\end{array}$ & \multicolumn{2}{|c|}{ Ingestion per $5 \mathrm{~min}$} & $\begin{array}{c}\text { Efficiency } \\
(\%)\end{array}$ \\
\hline \multicolumn{8}{|c|}{ Large copepods } \\
\hline $\mathrm{L}-\mathrm{Oe}$ & $1.6 \times 10^{0}$ & 0.7 & 0.2 & 18.2 & 62 & 0.12 & 207 \\
\hline $\mathrm{L}-\mathrm{OC}$ & $1.6 \times 10^{\circ}$ & 1.7 & 0.5 & 19.2 & 163 & 0.32 & 197 \\
\hline L-Od & $1.6 \times 10^{\circ}$ & 2.0 & 0.6 & 11.9 & 118 & 0.23 & 111 \\
\hline $\mathrm{L}-\mathrm{Ob}$ & $1.6 \times 10^{0}$ & 7.7 & 2.3 & $20.2 \pm 7.2$ & 773 & 1.53 & 179 \\
\hline L-Oa & $1.6 \times 10^{0}$ & 50.3 & 15.1 & $7.5 \pm 1.9$ & 1880 & 3.71 & 45 \\
\hline LSF-0 & $1.6 \times 10^{0}$ & 57.8 & 17.3 & $6.3 \pm 0.9$ & 1830 & 3.61 & 37 \\
\hline \multicolumn{8}{|c|}{ Intermediate copepods } \\
\hline IS-5 & $1.6 \times 10^{-5}$ & 29.3 & 4.4 & $2.2 \pm 0.6$ & 325 & 0.32 & 17 \\
\hline IS-Ob & $1.6 \times 10^{0}$ & 30.1 & 4.5 & $4.2 \pm 2.4$ & 631 & 0.62 & 34 \\
\hline IS $-8 b$ & $8.2 \times 10^{-8}$ & 34.0 & 5.1 & $1.2 \pm 0.9$ & 201 & 0.20 & 14 \\
\hline IS-Oa & $1.6 \times 10^{0}$ & 34.6 & 5.2 & $3.3 \pm 2.5$ & 565 & 0.56 & 24 \\
\hline IS-4 & $2.7 \times 10^{-4}$ & 41.6 & 6.2 & $2.2 \pm 1.0$ & 452 & 0.45 & 16 \\
\hline IS $-6 b$ & $2.0 \times 10^{-6}$ & 47.2 & 7.1 & $2.0 \pm 0.2$ & 469 & 0.46 & 15 \\
\hline IS-8a & $8.2 \times 10^{-8}$ & 53.0 & 7.9 & $1.1 \pm 0.7$ & 299 & 0.29 & 11 \\
\hline IS-6a & $2.0 \times 10^{-6}$ & 58.6 & 8.8 & $2.8 \pm 0.7$ & 813 & 0.80 & 20 \\
\hline \multicolumn{8}{|c|}{ Small copepods } \\
\hline IS-5 & $1.6 \times 10^{-5}$ & 33.7 & 1.0 & $2.2 \pm 0.6$ & 368 & 0.07 & 16 \\
\hline IS-Ob & $1.6 \times 10^{0}$ & 34.4 & 1.0 & $2.9 \pm 2.4$ & 504 & 0.10 & 24 \\
\hline LSF-O & $1.6 \times 10^{0}$ & 46.0 & 1.5 & $2.2 \pm 0.9$ & 499 & 0.10 & 13 \\
\hline IS-8b & $8.2 \times 10^{-8}$ & 47.9 & 1.4 & $0.8 \pm 0.9$ & 196 & 0.04 & 9 \\
\hline IS- 4 & $2.7 \times 10^{-4}$ & 48.4 & 1.5 & $2.4 \pm 1 . .0$ & 586 & 0.12 & 17 \\
\hline IS-8a & $8.2 \times 10^{-8}$ & 54.3 & 1.6 & $1.2 \pm 0.7$ & 326 & 0.06 & 11 \\
\hline IS-Oa & $1.6 \times 10^{0}$ & 56.2 & 1.7 & $2.5 \pm 2.5$ & 709 & 0.14 & 19 \\
\hline IS-6a & $2.0 \times 10^{-6}$ & 59.8 & 1.8 & $2.5 \pm 0.7$ & 736 & 0.15 & 17 \\
\hline IS-6b & $2.0 \times 10^{-b}$ & 63.3 & 1.9 & $2.1 \pm 0.2$ & 677 & 0.13 & 16 \\
\hline
\end{tabular}

class was also high and differed significantly from 4 of the other experiments $(p<0.05$; Table $7 \mathrm{~B})$.

Low light levels had a greater effect on feeding rates than on swimming speed. At the lowest light level, swimming speed while feeding $\left(32.2 \mathrm{~cm} \mathrm{~s}^{-1}\right)$ was $74 \%$ of the mean swimming speed $\left(43.1 \mathrm{~cm} \mathrm{~s}^{-1}\right)$ at higher light levels with the same prey. In comparison, the mean VSC at low light for the intermediate-sized copepods was only $31 \%$ of the mean at higher light levels.

\section{Effect of size upon feeding}

Ingestion rates while feeding on large copepods increased curvilinearly with increasing concentration (Fig. 5A). These rates increased from 62 copepods $\mathrm{fish}^{-1} 5 \mathrm{~min}^{-1}$ at the lowest concentration of $0.7 \mathrm{l}^{-1}$ to 1880 copepods fish $^{-1} 5 \mathrm{~min}^{-1}$ at a concentration of $50 \mathrm{I}^{-1}$ (Table 8, Fig. 5A). An Ivlev curve (Eq. 3) fitted to these data (SAS non-linear regression) with a threshold of 0.4 copepods $1^{-1}$ (the threshold concentration for termination of feeding) gave a maximum ingestion rate of 1970 copepods fish ${ }^{-1} 5 \mathrm{~min}^{-1}$ (Fig. 5A). The concentration at which $90 \%$ of this maximum rate was reached was 37.3 copepods $\mathrm{l}^{-1}$ The volume swept clear (VSC) increased to a maximum of $19.81 \mathrm{fish}^{-1} \mathrm{~min}^{-1}$ at a concentration of $3.7 \mathrm{1}^{-1}$ before declining at higher concentrations (Fig. 5B). At the highest concentration used in these experiments $\left(58 \mathrm{l}^{-1}\right)$, the VSC was $6.3 \mathrm{l} \mathrm{fish}^{-1}$ min $^{-1}$ (Table 8, Fig. 5B).

Clearance efficiency of the large copepods at the highest food concentration was $37 \%$, while at lower concentrations efficiencies were between 111 and $207 \%$ (Table 8). Efficiencies greater than 100\% indicate that the mackerel were actively searching and biting particles (particulate feeding) instead of filter feeding. The decreased efficiency at the highest concentration may indicate a tendency towards filter feeding or a limitation of ingestion rates due to handling time considerations.

Ingestion and clearance rates on intermediate and small copepods offered together were considerably lower than values observed when large copepods were offered alone at the same concentrations (Fig. 5). However, there were no differences between these 2 smaller size classes. Within each experiment, slopes of the regressions for each size class did not differ significantly (heterogeneity of means, $p>0.05$ ), and there 
was no difference between the overall mean VSCs calculated for each size class ( $t$-test, $\mathrm{p}>0.05$ ). There was no change in VSC with concentration of these intermediate and small size classes over the concentration ranges offered (Fig. 5B). Clearance rates for the 2 food types were grouped (excluding low-light experiments) and an overall mean of $2.61 \mathrm{fish}^{-1} \mathrm{~min}^{-1}$ was obtained.

The mean clearance efficiencies for intermediate and small size classes (excluding experiments at the lowest light level), were 20.8 and $18.3 \%$ respectively and were not significantly different ( $t$-test, $p>0.05$ ). The lack of any change in clearance rate with food concentration, together with the low clearance efficiencies, suggests that the mackerel were filter feeding on these smaller prey rather than actively searching and biting at them.

\section{Predation upon fish larvae}

In the experiments in which mackerel were offered young cod larvae alone, the mackerel did not initiate active feeding and apparently did not perceive them as food. In these 2 experiments, the concentrations of larvae ( 4 and $22 \mathrm{l}^{-1}$ ) should have been sufficient to stimulate active feeding In Expt LSF-0, where cod larvae were offered together with large and small copepods, the larvae were ingested at rates similar to the intermediate and small copepods (Fig. 5). Despite the relatively large size of the fish larvae, clearance rates were much lower than for large copepods at the same concentration. These results suggest that in this experiment the mackerel were actively searching for, and ingesting, the large copepods but were only consuming the small copepods and fish larvae incidentally.

\section{DISCUSSION}

These results demonstrate that the feeding behavior of Atlantic mackerel is strongly size-selective, a conclusion also reached by Pepin et al. (1988). This size selection is based on both the efficiency of retention of different-sized particles by the gill rakers, and a switch in feeding behavior from filter feeding to particulate feeding.

A number of marine planktivores switch between particulate feeding and filter feeding. These include Pacific and Atlantic mackerel (Scomber japonicus and $S$. scombrus), herring (Clupea harengus), and anchovies (Engraulis mordax, E. capensis and E. ringens). Typically these fish switch between filter feeding at high concentrations of small plankton prey to particulate feeding at lower concentrations of micronekton or large plankton prey. In addition, Pacific and Atlantic

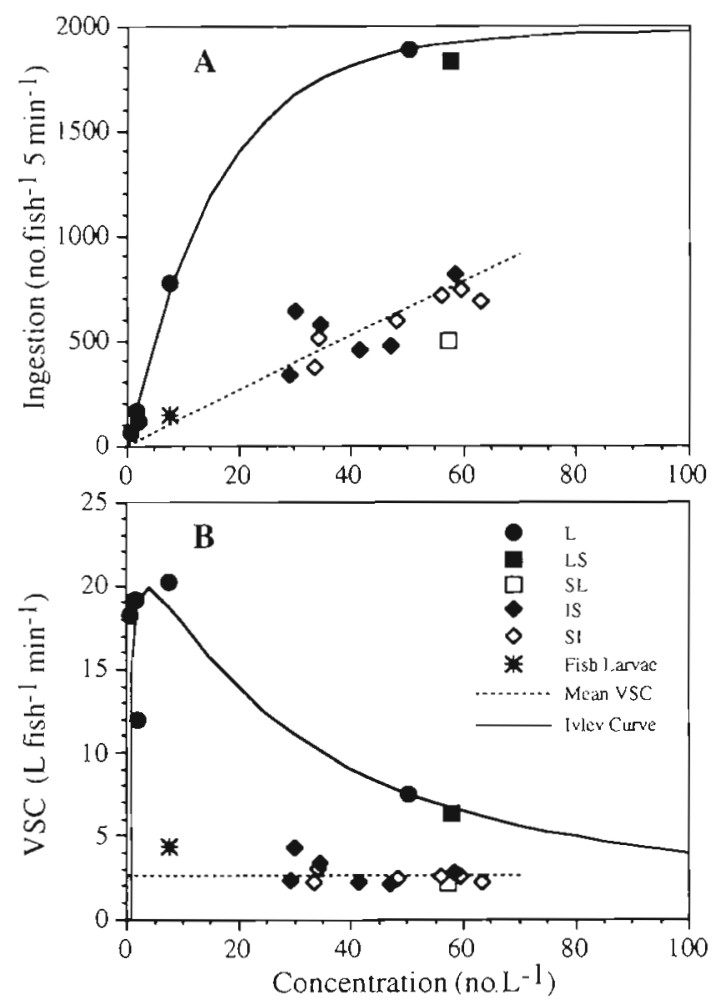

Fig. 5. Scomber scombrus. (A) Ingestion rate and (B) clearance rate, VSC, of Atlantic mackerel versus the geometric mean of the prey concentration. Prey types are indicated by letters, with any accompanying prey listed second (i.e. LS: Large copepods with Small copepods also present). Experiments at the lowest light level are not shown. The dashed line in (B) shows the mean VSC for intermediate and small copepods, and the mean ingestion rate calculated from this VSC is shown with a dashed line in (A). Solid lines show the Ivlev curve fitted to the VSC for large copepod prey and the ingestion rate data for this prey type In (A), the fitted Ivlev curve was: $I=1970\left[1-\mathrm{e}^{-0.0623 C_{1}-039 j}\right]$ copepods fish ${ }^{-1} 5 \mathrm{~min}^{-1}$

mackerel and herring (O'Connell \& Zweifel 1972, Gibson \& Ezzi 1985, Pepin et al. 1988) have been shown to switch from particulate to filter feeding at reduced concentrations of the same prey. In these studies, feeding behavior was classified based on the length of time the mouth was open during each feeding bout, with filter feeding defined as when the mouth was open $>0.2$ $\mathrm{s}$ (Gibson \& Ezzi 1985), $>0.5 \mathrm{~s}$ (Pepin et al. 1988) and 1 to 3 s (O'Connell \& Zweifel 1972). In these studies it was observed that swimming speeds were faster while filter feeding than while particulate feeding.

In the present experiments, we saw a similar transition from particulate feeding at low concentrations of large plankton prey to filter feeding at higher concentrations of the same prey. Determining the mode of feeding used by Atlantic mackerel while they are feeding on plankton-sized prey is difficult; the fish do not break their schooling pattern and change direction 
continually to attack prey while particulate feeding, as has been described for the anchovies Engraulis mordax (Leong \& O'Connell 1969) and E. capensis (James \& Findlay 1989). We used clearance rates and ingestion rates rather than the time the mouth. was open or swimming speeds as criteria.

The very high clearance rates at low concentrations of large copepods indicate that the mackerel were particulate feeding. Based on clearance efficiency, these rates were as much as twice the calculated maximum clearance rate of filter-feeding mackerel, based on their mouth area and swimming speed and assuming that they have their mouths open continuously and that particles were retained with $100 \%$ efficiency (Eq. 2, Table 8 ). In reality, neither of these criteria are likely to be met. While we have no way of determining the actual retention efficiency of the mackerel while filtering large plankton particles, it is likely to be less than $100 \%$. Visual observations indicated that the mackerel had their mouths open only about one-third to one-half of the time when feeding on the large copepods. Together these suggest that, if the mackerel were filter feeding, the actual clearance rates would be as low as 10 to $40 \%$ of our calculated maximum, and thus they would fall within the range observed with higher prey concentrations. Further evidence that the mackerel were particulate feeding was their slower swimming speeds when feeding on low concentrations of large copepods than when feeding on higher prey concentrations, regardless of size. This is consistent with previous observations of swimming speeds of particulate feeding planktivores (O'Connell \& Zweifel 1972, Gibson \& Ezzi 1985, Pepin et al. 1988).

At high concentrations of large copepods, the mackerel switched from particulate feeding to filter feeding. Clearance rates by the mackerel decreased (37 to $45 \%$ efficiency, Tabie 8) and were in the range expected for filter feeding. Ingestion rates of individual prey items increased to $6 \mathrm{~s}^{-1}$, a rate likely to be too high for individual acts of capture. This switch to filter feeding took place at an initial plankton concentration of between 24 and $64 \mathrm{l}^{-1}$ (L-0a and L-0b; Table 2). Herring feeding on the same large copepods (C5 and C6 Calanus finmarchicus) switch between filtering and particulate feeding at 18 copepods $\mathrm{l}^{-1}\left(95 \%\right.$ CI of 10 to $34 \mathrm{l}^{-1}$; Gibson \& Ezzi 1990), a similar concentration to that observed for the mackerel.

When offered intermediate and smaller prey items at relatively high concentrations the mackerel appeared to filter feed. In these experiments clearance rates and efficiencies were quite low, indicating filter-feeding behavior. In addition, there was no change in clearance rate with concentration; a change in clearance rate with concentration would indicate active biting or particulate feeding. Swimming speeds were also high during these experiments, which is consistent with observations described above for filter feeding. In the present study no experiments were carried out at low concentrations of the intermediate and small prey items so it is not known whether the mackerel would switch to particulate feeding with these prey categories. However, there is likely to be some minimum prey size below which it would not be energetically worthwhile to switch feeding mode (Crowder 1985). With the Cape anchovy Engraulis capensis this threshold was found to be about $0.7 \mathrm{~mm}$ (James \& Findlay 1989).

Although there were no differences in clearance rates while the mackerel were filter feeding on the intermediate and small copepods, there was a difference between the 2 smaller size classes and the large copepods. In Expt LSF-0, large and small copepods were present together. In this experiment, the concentrations and clearance rates of large copepods were similar to those in Expt L-Oa, in which the mackerel appeared to be filter feeding. Clearance rates for the large copepods were considerably higher (2.9 times) than for small copepods present at the same time (Fig. $5 B$ ). Since there should not be an active selection process during filter feeding, this suggests that the 2 smaller size classes were retained with a lower efficiency. Effect of size on gill-raker retention efficiency has been noted previously, including both obligate planktivores such as the Atlantic menhaden Brevoortia tyrannus (Durbin \& Dirbin 1975) and planktivores which exhibit both modes of feeding (Leong \& O'Connell 1969, O'Connell 1972, O'Connell \& Zweifel 1972, Gibson \& Ezzi 1985, James \& Findlay 1989).

Light intensity had little effect on feeding rates above $2.0 \times 10^{-6} \mu \mathrm{E} \mathrm{m}^{-2} \mathrm{~s}^{-1}$. Below this, at $8.2 \times 10^{-8} \mu \mathrm{E}$ $\mathrm{m}^{-2} \mathrm{~s}^{-1}$, the feeding rate dropped to nearly zero, although the fish still exhibited filtering behavior. The rapid decline in feeding rates between $10^{-6}$ and $10^{-8} \mu \mathrm{E}$ $\mathrm{m}^{-2} \mathrm{~s}^{-1}$ indicates that the light-intensity threshold for rapid filter feeding is about $10^{-7} \mu \mathrm{E} \mathrm{m} \mathrm{m}^{-2} \mathrm{~s}^{-1}$ (Fig. 5). At this threshold, feeding rates are $50 \%$ of the feeding rate in full light. An absolute threshold, at which the feeding rate is zero, was not found in this study; however, most filter feeding will occur at light intensities above this $50 \%$ threshold. The drop in VSC at the lowest light level $\left(8.2 \times 10^{-8} \mu \mathrm{E} \mathrm{m}^{-2} \mathrm{~s}^{-1}\right)$ coincided with the drop in swimming speed, but was proportionately much greater. This suggests that at the lowest light level the mackerel decreased the amount of time spent filtering The duration of filtering bouts could not be adequately quantified in these experiments, but the fish appeared to filter for shorter periods and were slower to react to prey at low light levels.

The light intensity feeding threshold is of the same order of magnitude as the light intensity threshold for schooling found for mackerel $\left(1.8 \times 10^{-7} \mu \mathrm{E} \mathrm{m}^{-2} \mathrm{~s}^{-1}\right.$; 
Glass et al. 1986j Given a feeding threshold of about $10^{-7} \mu \mathrm{E} \mathrm{m}^{-2} \mathrm{~s}^{-1}$, mackerel should be able to feed and school throughout the night. The $1 \%$ light depth on Georges Bank is about $30 \mathrm{~m}$ (O'Reilly et al. 1987), corresponding to an attenuation coefficient of about 0.15 . From Clarke \& Denton's (1962) diagram of light intensity versus depth, it appears that the fish would be able to feed at $70 \mathrm{~m}$ during full moon and at $40 \mathrm{~m}$ with starlight alone. Bioluminescence, with potential light intensities up to $10^{-6} \mu \mathrm{E} \mathrm{m} \mathrm{m}^{-2} 5^{-1}$ (Glass et al. 1986), could also provide sufficient light for schooling and feeding. If mackerel can feed at such low light intensities, it is unlikely that light has a major effect on filter feeding in the field.

The ingestion rate of mackerel feeding upon zooplankton will be much greater if they are particulate rather than filter feeding because of the much greater volume searched. From the observed maximum clearance rates while particulate feeding (20 l fish $\left.{ }^{-1} \mathrm{~min}^{-1}\right)$, assuming a copepod dry weight of $90 \mu \mathrm{g}$ (the mean of the intermediate and small size classes), the fish would have an ingestion rate of $0.7 \%$ body weight $\mathrm{h}^{-1}$ while particulate feeding on a concentration of about $2 \mathrm{I}^{-1}$. In contrast, if the mackerel were filter feeding at the mean observed rate of $2.61 \mathrm{fish}^{-1} \mathrm{~min}^{-1}$, a concentration of about $18 \mathrm{I}^{-1}$ would be required to attain the same ingestion rate. If the mackerel were particulate feeding on adult Calanus finmarchicus, which weigh about $500 \mathrm{\mu g}$ dry $w t$, the difference would be considerably greater.

Copepods are a significant part of the diet of mackerel on Georges Bank (Michaels 1981) and could be ingested either by particulate feeding or by filter feeding. Calanus finmarchicus is the biomass dominant on Georges Bank during late spring, constituting over $90 \%$ of the total zooplankton biomass (Davis 1987). On the southern flank of Georges Bank, average water column concentrations of $C$. finmarchicus copepodites during May and June were between $10^{4}$ and $10^{5} \mathrm{~m}^{-2}$ over the period 1977 to 1987 (Meise \& O'Reilly 1996). If we assume a $70 \mathrm{~m}$ water column, this corresponds to a concentration of between 143 and $1430 \mathrm{~m}^{-3}$, a concentration too low to stimulate feeding by mackerel according to our data. However, $C$. finmarchicus is very patchily distributed, with dense aggregations (up to 331 copepods $\mathrm{l}^{-1}$ ) observed during spring in the nearby southern Gulf of Maine (Wishner et al. 1988 , 1995). Depth-stratified sampling on the southern flank of Georges Bank during May 1996 has shown that $C$. finmarchicus copepodite concentrations may be as high as $12.3 \mathrm{~J}^{-1}$ (Durbin unpubl.). This latter concentration is high enough to initiate feeding, although perhaps not filter feeding. More information is needed on the relative abundance of patches of the different sized copepods before the relative significance of each feeding mode can be assessed.
Mackerel did not actively feed upon small cod larvae or select them when presented together with other prey, but took them incidentally while feeding on other prey. In 2 trials where 3 and 5 d old larvae (5 $\mathrm{mm}$ long) were offered alone, the mackerel did not feed upon them and apparently did not perceive them as prey. When they were offered together with 2 size classes of copepods at a concentration sufficient to stimulate filter feeding, the larvae were eaten, but the larval clearance rates were lower than for the large copepods; there was no active selection of the cod larvae by the mackerel.

Pepin et al. (1987) carried out experiments in which adult Atlantic mackerel were offered mixtures of naturally caught fish larvae 3 to $10 \mathrm{~mm}$ in length together with natural zooplankton assemblages. They found that larger larvae were positively selected. However, their data suggest that larvae $<5 \mathrm{~mm}$ in length are eaten at a lower rate which is not strongly dependent on larval size. In 3 experiments where the larvae were $>5 \mathrm{~mm}$, almost all of the larvae were eaten within the 5 min experimental trial. This suggests that the larger larvae were actively selected for whereas the smaller larvae were eaten incidentally while the fish were filtering the zooplankton. Pepin et al. (1987) also noted that predation rates on copepods of a given weight were generally 20 to $30 \%$ higher than predation rates on fish larvae of the same weight. These lower clearance rates of fish larvae were similar to our results. It would not be surprising if the mackerel were filtering their prey, since zooplankton with all of their appendages would likely be retained with greater efficiency than fish larvae. Pepin et al. (1987) did not carry out any experiments where fish larvae were present alone, but their results are consistent with our observation that small larvae are not actively selected by mackerel and are only taken incidentally while filter feeding on other plankton prey.

These results suggest that the impact of mackerel on small fish larvae on Georges Bank will depend greatly upon whether the mackerel are filter feeding or particulate feeding. As noted above, patch concentrations of copepods on Georges Bank are high enough to stimulate filter feeding. However, more information is needed on small-scale patches of Calanus finmarchicus and the extent to which they may stimulate filter feeding before a predation impact of mackerel on small fish larvae on Georges Bank can be calculated.

Acknowledgements. Funding was gratefully received from the National Oceanic and Atmospheric Administration Coastal Ocean Program Georges Bank Ecosystem Study under grant No. NA36RG0474 to Ann G. Durbin, E.G.D., and W.K.M. 


\section{LITERATURE CITED}

Batty RS, Blaxter JHS, Libby DA (1986) Herring (Clupea harengus) filter-feeding in the dark. Mar Biol 91:371-375

Blaxter JHS (1976) The role of light in the vertical migration of fish-a review. In: Evans GC, Bainbridge R, Rackham O (eds) Light as an ecological factor. II. Blackwell Scientific Publications, Oxford, p 189-210

BioScan (1992) OPTIMAS'M user guide. BioScan, Edmonds, WA

Clarke GL, Denton EJ (1962) Light and animal life. In: Hill MN (ed) The sea, Vol 1. John Wiley and Sons, New York, p $456-468$

Comita GW, Marshall SM, Orr AP (1966) On the biology of Calanus finmarchicus. XIII. Seasonal change in weight. calorific value and organic matter. J Mar Biol Assoc UK 46: $1-17$

Crowder LB (1985) Optimal foraging and feeding mode shifts in fish. Environ Biol Fish 12.57-62

Dartnall HJA, Lythgoe JN (1965) The spectral clustering of visual pigments. Vision Res 5:81-100

Davis CS (1987) Zooplankton life cycles. In Backus RH, Bourne DW (eds) Georges Bank. MIT Press, Cambridge, MA, p 256-267

Durbin AG (1979) Food selection by plankton feeding fishes. In: Clepper $\mathrm{H}$ (ed) Predator-prey systems in fisheries management. Sport Fishing Institute, Washington, DC, p 203-218

Durbin AG, Durbin EG (1975) Grazing rates of the Atlantic menhaden Brevoortia tyrannus as a function of particle size and concentration. Mar Biol 33:265-277

Gibson RN, Ezzi IA (1985) Effect of particle concentration on filter- and particulate-feeding in the herring Clupea harengus. Mar Biol 88:109-116

Gibson RN, Ezzi IA (1990) Relative importance of prey size and concentration in determining the feeding behaviour of the herring Clupea harengus. Mar Biol 107:357--362

Glass CW, Wardle CS, Mojsiewicz WR (1986) A light intensity threshold for schooling in the Atlantic mackerel, Scomber scombrus. J Fish Biol 29(Suppl A):71-81

Holanov SH, Tash JC (1978) Particulate and filter feeding in threadfin shad, Dorosoma petenense, at different light intensities. J Fish Biol 13:619-625

Hunter JR (1968) Effects of light on schooling and feeding of jack mackerel, Trachurus symmetricus. J Fish Res Bd Can 25:393-407

James AG, Findlay KP (1989) Effect of particle size and concentration on leeding behaviour, selectivity and rates of food ingestion by the Cape anchovy Engraulis capensis. Mar Ecol Prog Ser 50:275-294

Janssen J (1.978) Will alewives (Alosa pseudoharengus) feed in the dark? Environ Biol Fish 3:239-240

Krause J (1993) Positioning behaviour in fish schools: a costbenefit analysis. J Fish Biol 43(Suppl A):309-314

Lambert TC (1982) Techniques for the capture and handling of Atlantic mackerel with special reference to the use of quinaldine. Prog Fish Cult 44:145-147

Leong RJH, O'Connell CP (1969) A laboratory study of particulate and filter feeding of the northern anchovy (Engrauls mordax). J Fish Res Bd Can 26:557-582

Littell RC, Freund. RJ, Spector PC (1991) SAS System for Linear Models. SAS Institute Inc, Cary, NC

MacKay KT (1979) Synopsis of biological data of the northern population Atlantic mackerel (Scomber scombrus). Fisheries and Marine Service Technical Report \#885, St. Andrews, NB

McCree KJ (1981) Photosynthetically active radiation. In: Lange OL, Nobel PS, Osmond CB, Ziegler H (eds) Physiological plant ecology I, Vol 12A. Encyclopedia of plant physiology. Springer-Verlag, Berlin, p 41-55

Meise CJ, O'Reilly JE (1996) Spatial and seasonal patterns in abundance and age-composition of Calanus finmarchicus in the Gulf of Maine and on Georges Bank. Deep-Sea Res II 43:1473-1501

Michaels WL (1991) The impact of mackerel predation on the survival of pelagic age-zero sand lance, cod, and haddock on Georges Bank during spring of 1986. MSc thesis, Southern Massachusetts University, Dartmouth

Murphy JA, Cohen RE (1978) A guide to the developmental stages of common coastal, Georges Bank and Gulf of Maine copepods. Lab Ref No. 78-53. Northeast Fisheries Science Center, NMFS, Woods Hole, MA

Northeast Fisheries Science Center (NEFSC) (1995) Status of the fishery resources off the Northeastern United States for 1994. NMFS-NE-108, Woods Hole, MA

$\mathrm{O}^{\prime}$ Connell CP (1972) The interrelation of biting and filtering in the feeding activity of the northern anchovy (Engraulis mordax). J Fish Res Bd Can 29:285-293

O'Connell CP, Zweifel JR (1972) A laboratory study of particulate and filter feeding of the Pacific mackerel, Scomber japonicus. Fish Bull 70:973-981

O'Reilly JE, Evans-Zeitler C, Busch DA (1987) Primary production. In: Backus RH, Bourne DW (eds) Georges Bank MIT Press, Cambridge, MA, p 220-233

Pepin P, Koslow JA, Pearre S Jr (1988) Laboratory study of foraging by Atlantic mackerel, Scomber scombrus, on natural zooplankton assemblages. Can J Fish Aquat Sci 45:879-887

Pepin P, Pearre S Jr, Koslow JA (1987) Predation on larval fish by Atlantic mackerel, Scomber scombrus, with a comparison of predation by zooplankton. Can J Fish Aquat Sci 44 $2012-2018$

Sette OE (1950) Biology of the Atlantic mackerel (Scomber scombrus) of North America, Part II: Migrations and habits. Fish Bul.l Fish W].d.f Serv 51:251-358

Sutherland SJ (1996) Effects of light Intensity on the filterfeeding rates of Atlantic mackerel. MSc Thesis, University of Rhode Island, Kingston

Tande KS, Hopkins CCE (1981) Ecological investigations of the zooplankton community of Balsfjorden, northern Norway: the genital system in Calanus finmarchicus and the role of gonal development of overwintering strategy. Mar Biol 63:159-164

Vinogradov VI (1981) Daily rhythms and food rations of common pelagic fishes in Nantucket Shoals (New England) in the summer. Sov J Mar Biol 7(3): 170-174

Whitney RR (1969) Schooling of fishes relative to available light. Trans Am. Fish Soc 1969:497-504

Wishner KF, Durbin EG, Durbin AG, Macaulay MC, Winn HE, Kenney RD (1988) Copepod patches and right whales in the Great South Channel off New England. Bull Mar Sci 43:825-844

Wishner KF, Schoenherr JR, Beardsley R, Chen C (1995) Abundance, distribution and population structure of the copepod Calanus finmarchicus in a springtime right whale feeding area in the southwestern Gulf of Maine. Cont Shelf Res 15:475-507

Submitted: December 23, 1997; Accepted: July 16, 1998

Proofs received from author(s): October 7, 1998 